\title{
FORMULATION AND EFFECTIVENESS OF A HAND SANITIZER GEL PRODUCED USING SALAM BARK EXTRACT
}

\author{
SILVIA SURINI ${ }^{1 *}$, NURUL ISTI AMIRTHA ${ }^{1}$, DELLY CHIPTA LESTARI ${ }^{2}$ \\ ${ }^{1}$ Laboratory of Pharmaceutics and Pharmaceutical Technology Development, Faculty of Pharmacy, Universitas Indonesia, Depok, 16424, \\ Indonesia. ${ }^{2}$ Microbiology Clinic, Faculty of Medicine, Universitas Indonesia, Cikini, Jakarta, 10320, Indonesia.
}

Email: silvia@farmasi.ui.ac.id

Received: 27 June 2018, Received and Accepted: 18 October 2018

ABSTRACT

Objective: The objectives of this study were to determine the minimum inhibitory concentration (MIC) of Salam bark extract against Staphylococcus aureus, formulate and evaluate hand sanitizer gels containing Salam bark extract, and determine the effectiveness of the gels against bacteria on the palms of the hands.

Methods: The gel base was optimized by preparing three formulations containing carbomer and triethanolamine at ratios of $0.25 \%: 0.5 \%$, $0.5 \%: 1 \%$, and $0.5 \%: 2 \%$. The best gel formulation was mixed with Salam bark extract. The physical stability of gels containing $4.04 \%$ (formulation 1 ) and $7.77 \%$ (formulation 2) Salam bark extract was measured at $4 \pm 2{ }^{\circ} \mathrm{C}, 27 \pm 2^{\circ} \mathrm{C}$, and $40 \pm 2^{\circ} \mathrm{C}$ for 12 weeks. The effectiveness of the gels was examined on the palms of 30 respondents.

Results: The MIC of Salam bark extract was 3.12\%. The best gel base contained carbomer and triethanolamine at a ratio of $1-4$ and a pH of 5.50. Formulations 1 and 2 gels had good stability for 12 weeks. Formulation 2 tended to decrease the number of bacteria ( $\mathrm{p}=0.125$ ) better than formulation $1(\mathrm{p}=1.000)$. In the hedonic study, formulation 2 was preferred to formulation 1 .

Conclusion: Formulation 2 gel with $7.77 \%$ Salam bark extract was more effective than formulation 1 gel with $4.04 \%$ extract in decreasing the number of bacteria on the palms.

Keywords: Antibacterial, Hand sanitizer, Minimum inhibitory concentration, Physical stability, Salam bark extract.

(C) 2018 The Authors. Published by Innovare Academic Sciences Pvt Ltd. This is an open access article under the CC BY license (http://creativecommons. org/licenses/by/4. 0/) DOI: http://dx.doi.org/10.22159/ijap.2018.v10s1.48

\section{INTRODUCTION}

Ethanol extract of Salam bark contains flavonoids and tannins that can inhibit the growth of Staphylococcus aureus, producing an inhibition zone $(13.67$ and $12.33 \mathrm{~mm}$ ) that is larger than the inhibition zone produced by ethanol extract of Salam leaf (8.75 and $9.34 \mathrm{~mm}$ ) [1]. It is not known whether the minimum inhibitory concentration (MIC) of ethanol extract of Salam bark can inhibit S. aureus [1].

S. aureus is a bacterium that often causes infection in humans. A hand sanitizer gel of Salam bark extract has been developed to prevent the spread of the bacteria on the palms. The gel is easy to apply and is acceptable to people $[2,3]$.

The objective of this study was to determine the MIC against S. aureus of ethanol extract of Salam bark. After the MIC was determined, hand sanitizer gel was prepared with two different concentrations of Salam bark extract. The antibacterial effectiveness of the gels was examined on the palms of the respondents, and the number of bacteria was calculated.

\section{METHODS}

Ethanol extract of Salam bark was purchased from the Spice and Medicinal Crops Research Institute (BALITRO, Indonesia). Pure culture of S. aureus ATCC 25923, brain heart infusion (BHI), McFarland standard, thioglycolate medium, agar medium, nutrient broth, and agar blood medium were purchased from the microbiology clinic of the Faculty of Medicine, Universitas Indonesia. Ethanol 96\% was purchased from Brataco, Indonesia; carbomer from Lubrizol, South Korea; tetraethylammonium from Brataco, Indonesia; propylene glycol from Brataco, Indonesia; isopropyl myristate from Brataco, Indonesia; aqua destillata from Brataco, Indonesia; vortex from Thermo Fisher Scientific, USA; homogenizer from IKA Germany; incubator from Memmert, Germany; autoclave from Hirayama, Japan; hot plate from IKA Germany; pH meter from Eutech pH 510, Singapore; viscometer (RION viscometer VT-04) from Brookfield; penetrometer from Industrial Glasswares, India; digital balance (Lutron GM-300P) from Lutron Electronics, USA; colony counter from Funke Gerber, Germany; and refrigerator from Toshiba, Japan.

Determination of minimum inhibitory concentration of Salam bark extract

An appropriate amount of Salam bark extract was dissolved in aqua destillata to produce a concentration of $500 \mathrm{mg} / \mathrm{mL}$. S. aureus broth was also prepared to yield a solution with equivalent turbidity as McFarland standards solution [1,2].1 ml of the bark extract solution was transferred into a tube containing $1 \mathrm{~mL}$ of BHI. The mixture was vortex mixed, and $1 \mathrm{~mL}$ was aliquoted and transferred into another tube containing $1 \mathrm{~mL}$ of $\mathrm{BHI}$ and vortex mixed. The process was repeated to produce seven serial dilutions of extract solution in BHI. To the seven serial dilutions, $10 \mu \mathrm{L}$ of the broth solution of $S$. aureus was added. The tubes were again vortex mixed. Three other tubes were prepared; one was filled with $1 \mathrm{~mL}$ of $\mathrm{BHI}$, another with $1 \mathrm{~mL}$ of extract, and the other with BHI plus bacteria. All the tubes were then incubated at $37^{\circ} \mathrm{C}$ for $18-24 \mathrm{~h}$.

\section{Gel base optimization}

Gel base was prepared by varying the proportion of carbomer to triethanolamine in the gel, which also contained propylene glycol, isopropyl myristate, aqua destillata, and fragrance (clove). The carbomer-to-triethanolamine ratio was varied to obtain the optimum composition of formulations $\mathrm{A}, \mathrm{B}$, and $\mathrm{C}$. The optimum composition was determined according to a $\mathrm{pH}$ that was comparable to skin $\mathrm{pH}$ and a fluid consistency suitable for application to the skin. The composition of the three formulations is shown in Table 1. 
Formulations 1 and 2 contained the Salam bark extract at concentrations of $4.04 \%$ and $7.77 \%$, respectively.

\section{Formulation}

The optimum ratio of carbomer to triethanolamine was found to be 1:4. This ratio was used to formulate the hand sanitizer gel by mixing the components in appropriate proportions, as shown in Table 2. The negative control gel was formulated using the exact same formulation but without the extract.

\section{Evaluation}

The gels were evaluated for organoleptic properties, viscosity, and rheology including flow characteristics, consistency, $\mathrm{pH}$, homogeneity, antibacterial activity, and hedonic characteristics.

The effectiveness and hedonic characteristics of the gels were examined in a study involving 30 respondents. For the effectiveness study, the respondents were asked to apply the gel to their palms. Before the application of the gel, a swab sample from the palm was obtained and inoculated into a growth medium. After 1-2 min wearing the gel, the palms were again swabbed to obtain an inoculum that was inoculated into a growth medium [4]. The bacteria count was done on a colony counter, and the results were analyzed by the McNemar test. In the hedonic study, the respondents blindly rated five characteristics of the hand sanitizer gel: Odor, color, texture, stiffness, and rate of drying [5].

The physical stability of the gel was evaluated at temperatures of $4 \pm 2^{\circ} \mathrm{C}$, $27 \pm 2^{\circ} \mathrm{C}$, and $40 \pm 2^{\circ} \mathrm{C}$. Organoleptic properties, $\mathrm{pH}$, and homogeneity were determined every 2 weeks. Viscosity and consistency were determined at weeks 0 and 12 of storage. The gels were subjected to cycling test examination for six cycles, which were stored at $4 \pm 2{ }^{\circ} \mathrm{C}$ for $24 \mathrm{~h}$, then at $40 \pm 2^{\circ} \mathrm{C}$ for another $24 \mathrm{~h}$. After each cycle, the gels were observed for physical changes [6].

\section{RESULTS}

\section{Determination of MIC}

Table 3 shows the growth of bacteria inoculated in serially diluted extract containing broths. The experiments were performed in duplicate, and bacterial growth begins to appear at broth concentrations of $<3.12 \%$.

\section{Gel base optimization}

The various gel bases were also tested for $\mathrm{pH}$. Formulations $\mathrm{A}, \mathrm{B}$, and $\mathrm{C}$ had $\mathrm{pH}$ values of $4.10,4.55$, and 5.50 , respectively. Although the

Table 1: Formulation of gel base

\begin{tabular}{llll}
\hline Ingredients & \multicolumn{2}{l}{ Formulation } & \\
\cline { 2 - 4 } & A & B & C \\
\hline Carbomer (\%) & 0.25 & 0.5 & 0.5 \\
Triethanolamine (\%) & 0.5 & 1 & 2 \\
Propylene glycol (\%) & 15 & 15 & 15 \\
Isopropyl myristate (\%) & 1 & 1 & 1 \\
Aqua destillata (mL) & 100 & 100 & 100 \\
\hline
\end{tabular}

$\mathrm{pH}$ of formulation $\mathrm{C}$ was the closest to that of the skin, formulation $\mathrm{B}$ was selected for the next formulation due to its suitable physical characteristics for Salam bark extract gel formulation.

\section{Evaluation of hand sanitizer gel}

Table 4 shows the evaluation of the gels' physical characteristics including color, odor, sineresis, and homogeneity.

Fig. 1 shows the gel rheogram at week 0 . The consistency of the negative control, formulation 1 , and formulation 2 gels at week 0 can be seen from the cone penetration depth value and yield value. The cone penetration depth values of the negative control, formulation 1 , and formulation 2 gels were 373, 360, and $365 \mathrm{~mm}$, respectively. The yield values of the negative control, formulation 1 , and formulation 2 gels were $2653.332,2848.415$, and 2770.911 dyne $/ \mathrm{cm}^{2}$, respectively. The $\mathrm{pH}$ values of the negative control, formulation 1 , and formulation 2 gels were $5.50,6.33$, and 6.60 , respectively.

Table 5 shows the number of bacteria before and after application of formulations 1 and 2 . The data in Table 5 were processed using the Statistical Package for the Social Sciences with a non-parametric test (McNemar test). The formulation 2 gel tended to decrease the number of bacteria $(\mathrm{p}=0.125)$ better than the formulation 1 gel $(p=1.000)$.

Fig. 2 shows the hedonic study results from 30 respondents for formulations 1 and 2, including five characteristics (odor, color, texture, stiffness, and rate of drying).

\section{Physical stability}

The color, odor, and homogeneity of the three formulations were stable and sineresis did not occur after 12 weeks of storage at $4 \pm 2{ }^{\circ} \mathrm{C}$, $27 \pm 2^{\circ} \mathrm{C}$, and $40 \pm 2^{\circ} \mathrm{C}$. The $\mathrm{pH}$ of the negative control, formulation 1 , and formulation 2 tended to decrease during 12 weeks of storage at these temperatures (Fig. 3).

The viscosity results showed that the three formulations tended to be stable after 12 weeks of storage at $4 \pm 2^{\circ} \mathrm{C}, 27 \pm 2^{\circ} \mathrm{C}$, and $40 \pm 2^{\circ} \mathrm{C}$. The stability was shown by the viscosity friction values, which were $1.96 \%, 10.47 \%$, and $4.25 \%$ for the negative control, formulation 1 , and formulation 2, respectively. The consistency of the negative control, formulation 1 , and formulation 2 tended to increase during 12 weeks of storage at the above-mentioned temperatures.

The viscosity results showed that the three formulations tended to be stable after 12 weeks of storage at $4 \pm 2^{\circ} \mathrm{C}, 27 \pm 2^{\circ} \mathrm{C}$, and $40 \pm 2^{\circ} \mathrm{C}$. The stability was shown by the viscosity friction values, which were $1.96 \%, 10.47 \%$, and $4.25 \%$ for the negative control, formulation 1 , and formulation 2, respectively. The consistency of the negative control, formulation 1, and formulation 2 tended to increase during 12 weeks of storage at the above-mentioned temperatures.

\section{DISCUSSION}

This study found that the MIC of Salam bark extract for $S$. aureus was $3.12 \%$. As we could shown in Table 3, the solution performed the clearness began from $3.12 \%$ concentration.

Table 2: Formulation of hand sanitizer gel

\begin{tabular}{llll}
\hline Ingredients & Formulation 1 & Formulation 2 \\
\hline Ethanol extract of Salam bark (g) & 5 & 10 & Negative control \\
Carbomer (g) & 0.5 & 0.5 & 2 \\
Triethanolamine (g) & 2 & 15 & 0.5 \\
Propylene glycol (g) & 15 & 1 & 2 \\
Isopropyl myristate (g) & 1 & 0.25 \\
Clove fragrance (mL) & 0.25 & 100 & 15 \\
Aqua destillata (mL) & 100 & 128.75 \\
Total (g) & 123.75 & 0.25 \\
\hline
\end{tabular}


Table 3: Minimum inhibitory concentration of Salam bark extract

\begin{tabular}{|c|c|c|c|c|c|c|c|}
\hline \multirow[t]{3}{*}{ Trial } & \multicolumn{7}{|c|}{ Test tube number } \\
\hline & 1 & 2 & 3 & 4 & 5 & 6 & 7 \\
\hline & $50 \%$ extract & $25 \%$ extract & $12.5 \%$ extract & $6.25 \%$ extract & $3.12 \%$ extract & $1.56 \%$ extract & $0.78 \%$ extract \\
\hline 1 & Clear & Clear & Turbid & Clear & Clear & Turbid & Turbid \\
\hline 2 & Clear & Clear & Clear & Clear & Clear & Turbid & Turbid \\
\hline
\end{tabular}

Table 4: Organoleptic qualities and homogeneity of hand sanitizer gels

\begin{tabular}{llll}
\hline Formulation* & Color & Odor & Homogeneity \\
\hline 1 & Coral (Pantone RGB 255-127-80) transparent & Clove & None \\
2 & Dark red (Pantone RGB 139-0-0) transparent & Clove & None \\
NC & Transparent & Clove & None \\
\hline
\end{tabular}

*Formulation 1, 4.04\% extract; formulation 2, 7.77\% extract; NC, without extract. NC: Negative control

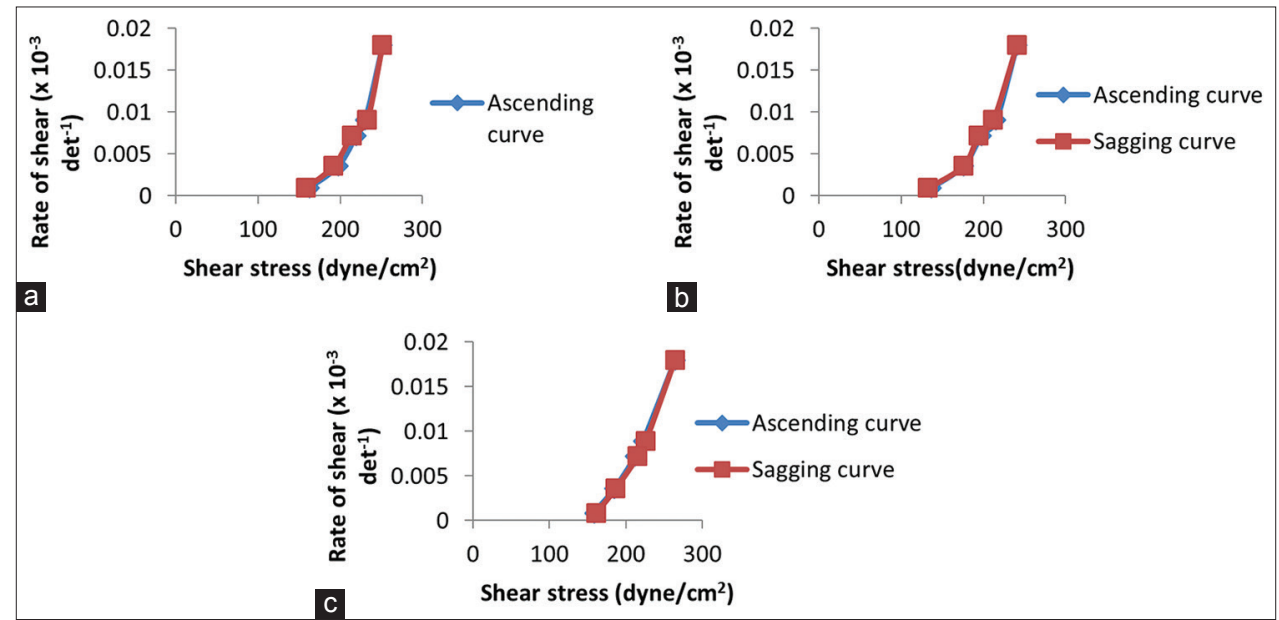

Fig. 1: Flowability curve of hand sanitizer gels: (a) negative control, (b) formulation 1, and (c) formulation 2 at week 0

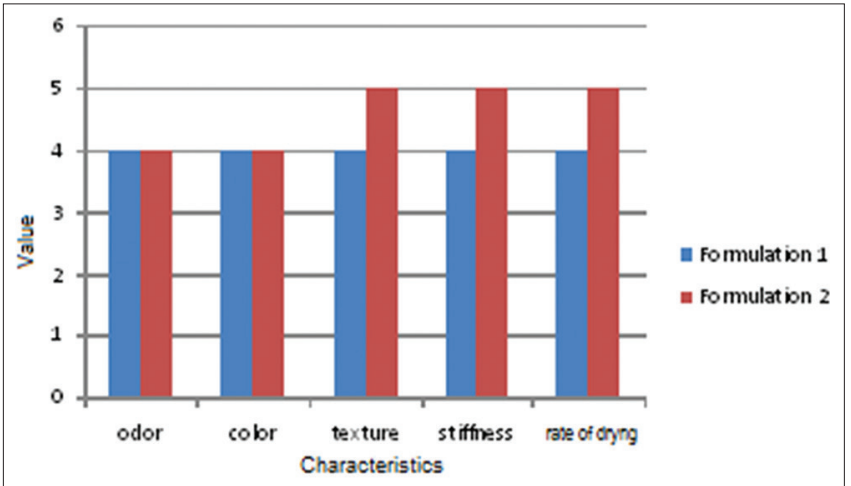

Fig. 2: Hedonic study values of formulations 1 and 2 hand sanitizer gel

The three formulations that were produced were transparent and no sineresis occurred, indicating that the gels had good characteristics. This result is in accordance with the literature. Based on Indonesia's Cosmetics Formularium (1985), the allowable colors of gels range from transparent to opaque [7]. According to Wijayanto et al., one of the characteristics of a good gel is that no sineresis occurs [8].

Another good characteristic of the three formulations was that the Salam bark extract contained in the gels was evenly dispersed, indicating that the dosage of Salam bark extract was available in every application of the gel.
The viscosity values of formulation 1 , formulation 2 , and the negative control at week 0 obtained using spindle number 5 with a speed of $2 \mathrm{rpm}$ were 48,000, 47,000, and 51,000 cps, respectively. The viscosity of all three formulations met Zatz and Kushla's standard for a good hand sanitizer gel of 47-150 dPa.s or 47,000-150,000 cps [9]. The three formulations were plastic and would flow when the yield value was reached. Based on the consistency of cone penetration depth, the negative control, formulation 1 , and formulation 2 were able to withstand forces of 2653.332, 2848.415, and 2770.911 dyne $/ \mathrm{cm}^{2}$, respectively.

The $\mathrm{pH}$ values of the negative control, formulation 1 , and formulation 2 were stable since the extract tended to be stable at an alkaline $\mathrm{pH}$. As the $\mathrm{pH}$ increased, the concentration of hydrogen ions in the medium decreased so that hydrogen ion released occurs by phenolic compounds in which the $\mathrm{pH}$ of protection increased for the phenolic compound except at $\mathrm{pH} 4$ [10]. The negative control and formulation 1 met the standards for good gel characteristics by having a $\mathrm{pH}$ similar to that of human skin $\mathrm{pH}$ so that they would not irritate the skin when used. Formulation 2 had a $\mathrm{pH}>7$ and was still tolerated by the skin; Hasyim and Baharudin reported that preparations with a $\mathrm{pH}$ of $>6.5$ could still be tolerated by the skin [11]. A good gel pH is almost the same as or closes to skin $\mathrm{pH}$, which ranges from 4.5 to 6.5 [12].

In the results of antibacterial activity, the number of bacteria sometimes exceeded 300 so that the paired $t$-test could not be used in the statistical analysis. The bacterial counts were, therefore, changed from numerical to categorical data. The grouping of bacterial counts was based on the World Health Organization (WHO) guidelines on hand hygiene in 
health care (WHO, 2009). According to the guidelines, the number of normal flora on the palms ranges from 0 to 300 . Therefore, the data on the number of bacteria on the palms were divided into two categories, Group 1 with $>300$ bacteria and Group 2 with $\leq 300$ bacteria.

Palms on which fungus growth was found were put in the "bad" category (>300). After they were categorized, we calculated the frequency of the two formulations before and after the application. Then, the non-parametric McNemar test was conducted. The McNemar test was chosen because the test is suitable for processing two related categorical variables. The McNemar test a non-significant difference between the decrease of bacteria in formulation 1 and formulation 2 before and after the application. However, the results of statistical analysis showed that formulation 2 was more effective

Table 5: Number of bacteria

\begin{tabular}{|c|c|c|c|}
\hline \multirow[t]{2}{*}{ Sample No. } & \multicolumn{2}{|c|}{ Formulation 1} & \multirow{2}{*}{$\begin{array}{l}\text { Formulation } 2 \\
\text { Before }\end{array}$} \\
\hline & Before & After & \\
\hline 1 & $>300$ & $>300$ & $>300$ \\
\hline 2 & 124 & 63 & 124 \\
\hline 3 & 262 & $>300$ & 262 \\
\hline 4 & 214 & 109 & 214 \\
\hline 5 & 289 & 147 & 289 \\
\hline 6 & 31 & 19 & 31 \\
\hline 7 & $>300$ & $>300$ & $>300$ \\
\hline 8 & 130 & 69 & 130 \\
\hline 9 & $>300$ & $>300$ & $>300$ \\
\hline 10 & $>300$ & $>300$ & $>300$ \\
\hline 11 & 59 & 35 & 59 \\
\hline 12 & 151 & 81 & 151 \\
\hline 13 & $>300$ & $>300$ & $>300$ \\
\hline 14 & 180 & 97 & 180 \\
\hline 15 & 145 & $>300$ & 145 \\
\hline 16 & 154 & 85 & 154 \\
\hline 17 & $>300$ & $>300$ & $>300$ \\
\hline 18 & $>300$ & 190 & $>300$ \\
\hline 19 & 236 & 127 & 236 \\
\hline 20 & 54 & 37 & 54 \\
\hline 21 & 147 & 84 & 147 \\
\hline 22 & $>300$ & $>300$ & $>300$ \\
\hline 23 & Fungus & Fungus & Fungus \\
\hline 24 & $>300$ & $>300$ & $>300$ \\
\hline 25 & 16 & 20 & 16 \\
\hline 26 & $>300$ & $>300$ & $>300$ \\
\hline 27 & $>300$ & $>300$ & $>300$ \\
\hline 28 & 89 & 59 & 89 \\
\hline 29 & $>300$ & $>300$ & $>300$ \\
\hline 30 & 115 & 72 & 115 \\
\hline
\end{tabular}

than formulation 1. This may due to several conditions. There may be other microbes besides $S$. aureus on the palms whose growth was not inhibited by the hand sanitizer gel tested; these could include Staphylococcus epidermidis, diphtheroids, streptococci, Pseudomonas aeruginosa, various anaerobic bacteria, Candida sp., and various species of fungus [13]. The duration of the swab collection after the application of the formulation may not have been accurately calculated. There may have been differences in the condition of the respondents' palms before application of the gel. Finally, the number of respondents may have been too small to show a statistically significant difference.

In the hedonic study, the respondents generally preferred formulation 2 due to its comfortable texture, non-stickiness, and fast drying after application. For the assessment of the aroma and color characteristics, the two formulations were judged to be almost identical. In future formulations, it was recommended that the fragrance (clove) should be reduced or replaced by another fragrance, while for the color characteristics can be used to beautify the color of the dosage.

The three formulations showed consistent improvement during storage. Increased consistency was due to the increased viscosity of the dosage after storage of the preparation for 12 weeks. The $\mathrm{pH}$ of the Salam bark extract decreased because $0.1 \%$ ascorbic acid was not added in the maceration process. Ascorbic acid in the extraction process would prevent the oxidation of phenolic groups, which are widely present in tannin compounds [14]. The viscosity increased in formulations 1 and 2 and remained stable in the negative control. At week 0 , we observed a random molecular structure that may have been caused by high-speed rotation during manufacture, but after 12 weeks of storage, the gel molecular structure changed more slightly. Only formulation 1 had a viscosity shift of $>10 \%$, but it was considered stable because the shift was not considered important. According to Zatz and Kushla, preparations are considered to have good stability if they have a viscosity shift of $<10 \%$ [9]. The change in the viscosity value of the gel preparation did not affect the flow properties of the dosage, which was still plastic and sufficiently dilute properties with the value of the viscosity present. Thus, it could be said that the gel preparations were stable and complied with standards for good gel characteristics. Formulation 1, formulation 2 , and the negative control were still stable at week 12 with high viscosity that could withstand forces of 2929.217, 3193.378, and 2801.528 dyne $/ \mathrm{cm}^{2}$, respectively.

In the cycling test, the three formulations did not show color changes, sineresis, or other forms of instability. This indicates that the gel preparations were stable, and degradation of their compounds did not occur due to stress, as proposed by the International conference of harmonization (2003).

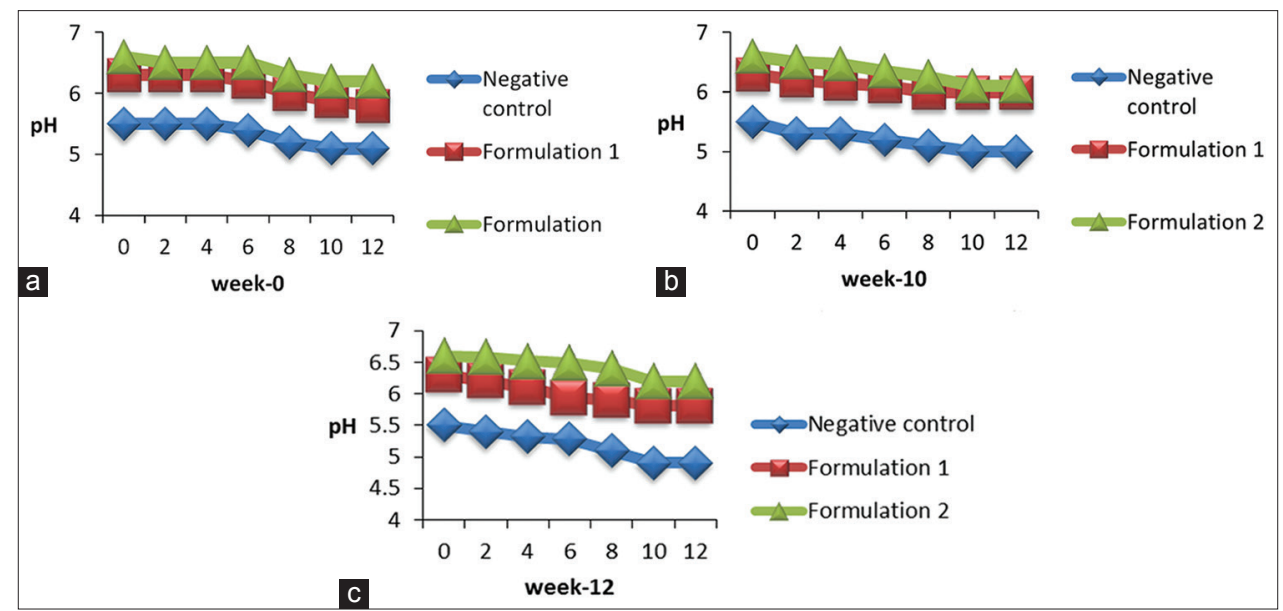

Fig. 3: (a-c) Changes in $\mathrm{pH}$ of negative control, formulation 1, and formulation 2 during 12 weeks of storage at $4 \pm 2^{\circ} \mathrm{C}, 27 \pm 2^{\circ} \mathrm{C}$, and $40 \pm 2^{\circ} \mathrm{C}$ 


\section{CONCLUSION}

The MIC of Salam bark extract was 3.12\%. Gel formulations containing $4.04 \%$ and $7.77 \%$ Salam bark extract showed good physical stability after 12 weeks of storage. Formulation 2 with $7.77 \%$ Salam bark extract was more effective than formulation 1 with $4.04 \%$ extract in decreasing the number of bacteria on the palms.

\section{ACKNOWLEDGMENTS}

All authors acknowledge Universitas Indonesia for support and PITTA Research Grants 2017.

\section{CONFLICTS OF INTEREST}

All authors declare that they have no conflicts of interest.

\section{REFERENCES}

1. Putra A, Masri ME. Test the effect of antibacterial extract of ethanol bark of salam stem [Syzigium polyanthum (Wight) Walp] against Staphylococcus aureus and Escherichia coli in in vitro. J Kesehatan Andalas I 2015;2015:500.

2. Benjamin DT. Introduction to Handsanitizers; 2010. Available from: http://www.antimicrobialtest laboratories.com/information_about handsanitizers.html

3. Centres for Disease Control and Prevention. Hand Sanitizer Ingredients; 2009. Available from: http://www.hand-sanitizer-dispenserreview.com/ hand-sanitizer-ingredients.htm. [Last accessed on 2016 Jan 20].

4. Radji M, Suryadi H, Ariyanti D. Test Antimicrobial Effectiveness of
Some Trademarks of Antiseptic Hand Cleansers. Depok: Faculty of Pharmacy, Universitas Indonesia; 2007.

5. Hartatik P. Formulation of Antiseptic Gel Preparation of Essential Lavender Flower Oil (Lavandula angustifolia Miller) with Carbopol Base and Antibacterial Activity Against Staphylococcus aureus. Thesis. Surakarta: Faculty of Pharmacy, Universitas Muhammadiyah; 2014.

6. Lateh MS. Formulation of Gel Sanitizer Handicraft Preparation of Ethanol Acid Gelugur Fruit (Garcinia atroviridis Griff. Et Anders) as Antibacterial to Staphylococcus aureus. Surakarta: Faculty of Pharmacy, Universitas Muhammadiyah; 2015.

7. Department of Health, Republic of Indonesia. Formulary Cosmetics Indonesia. Jakarta: Department of Health, Republic of Indonesia; 1985.

8. Wijayanto B, Kurniawan D, Sobri I. Formulation and Effectiveness of Hand Antiseptic Gel of Galangal Essential Oil. Purwokerto: Universitas Jendral Soedirman; 2013.

9. Zatz JL, Kushla GP. Gel. In: Lieberman HA, Rieger MM, Banker GS, editors. Pharmacheutical Dosage Form: Disperse System. $2^{\text {nd }}$ ed. New York: Marcel Dekker; 1996. p. 399-421.

10. Tensiska C. Antioxidant activity of andaliman fruit extracts in several food systems and the stability of their activity on temperature and $\mathrm{pH}$ conditions. J Food Technol Indust 2003;14:3-4.

11. Hasyim NF, Baharudin GA. Gel formulation of starfruit juice. Majalah Farmasi Farmakol 2011:15:5-9.

12. Heather AE, Adam CW. Transdermal and Topical Drug Delivery: Principles and Practice. 1st ed. New Jersey: Wiley; 2012. p. 432

13. Todar K. The Normal Bacterial Flora of Humans. University of Wisconsin: Department of Bacteriology; 2008. Available from: http// www.textbookofbacteriology.net/index.html.

14. Harborne J. Phytochemical Method: A Guide to Modern Way to Analyze Plants. $2^{\text {nd }}$ ed. Bandung: ITB Journal Publisher; 2006. 